\title{
El dilema del patrimonio paleontológico: ¿es posible su protección a través de las leyes de conservación de espacios naturales?
}

Rafael Marquina Blasco, Francisco Javier Ruiz Sánchez | Área de Paleontología, Universitat de València y Museu Valencià d'Història Natural

URL de la contribución <www.iaph.es/revistaph/index.php/revistaph/article/view/4194>

El marco jurídico sobre la protección y gestión del patrimonio paleontológico presenta una clara dicotomía (RUIZ-SÁNCHEZ, 2005). Al igual que en el resto del estado español, en la Comunidad Valenciana esta gestión puede realizarse bien a través de la legislación de patrimonio cultural (LEY 4/1998) o de las leyes de protección del patrimonio natural (LEY 11/1994). Esta situación crea un interesante debate sobre si los bienes paleontológicos deben ser gestionados dentro del patrimonio histórico o del patrimonio natural. De acuerdo a su origen y naturaleza, no tendría sentido la inclusión de los yacimientos paleontológicos y sus fósiles dentro del marco histórico-cultural. Sin embargo, relacionando los fósiles con el componente netamente cultural humano y la ambigüedad que recoge la legislación de patrimonio histórico, su gestión puede, como de hecho así ocurre, delegarse en el ámbito cultural incluso sin tener una clara componente cultural. No obstante, y a pesar de todo ello, no hay que olvidar que la totalidad de los restos fósiles se adscriben a biotas pretéritas con escasa o nula conexión con el campo cultural humano. Por otra parte, y desde un punto de vista eminentemente práctico, es necesaria valorar la tradicional coincidencia de los bienes paleontológicos con otros elementos del patrimonio natural (formaciones geológicas, ecosistemas,...). Así, la gestión del punto fosilífero dentro de otras figuras de protección ajenas al ámbito medioambiental puede crear una situación de descoordinación entre las administraciones competentes. Entendemos que por su naturaleza, los bienes paleontológicos estarían adscritos al patrimonio natural, hecho que viene apoyado en: a) son singularidades geológicas de origen totalmente natural; b) son un elemento más del entorno geológico, y por tanto están ligados al entorno natural colindante, de forma que su protección y gestión debe entenderse dentro del marco medioambiental (MORALES; AZANZA, 1997); y c) dado que la mayoría de restos fósiles se encuentran dentro de zonas con alguna categoría de protección dentro del marco legislativo medioambiental resultaría práctico que el patrimonio paleontológico quedara englobado en éste.

No obstante, y a pesar de lo argumentado con anterioridad, no se puede obviar lo establecido en cuanto a protección y ordenación de los yacimientos paleontológicos establecidos en la Ley 4/1998 de Patrimonio Cultural Valenciano y sus modificaciones. De esta forma, todos los bienes e inmuebles paleontológicos son parte integrante del patrimonio histórico, mientras que aquellos elementos más relevantes serán efectivamente protegidos (CASTILLO; CASTILLO; COELLO et ál., 1999). Así pues, al amparo de ambas leyes existen varias figuras de protección susceptibles de acoger la protección de un yacimiento paleontológico y de los fósiles en ellos contenidos. Según el Artículo 2 de la Ley 4/1998 de Patrimonio Cultural Valenciano podrán ser declarados como bienes de interés cultural valenciano (BICV) aquellos que presentan "singulares características y relevancia para el patrimonio cultural", y según dispone el artículo 26.1.f, aquel BIC “....donde existe un conjunto de fósiles de interés científico o didáctico" podrá ser considerado como zona paleontológica. Hasta la fecha, en la Comunidad Valenciana son escasos los ejemplos de yacimientos declarados como tales, restringiéndose en su mayoría a yacimientos de icnitas de dinosaurios. Por otra parte, tal 
a debate El marco legal para la protección del patrimonio paleontológico. ¿Qué pasa en tu comunidad?

y como dispone el artículo 15 de la citada ley, la administración autonómica debe elaborar y mantener actualizado el Inventario General del Patrimonio Cultural Valenciano. En el caso concreto del patrimonio paleontológico se materializó con la creación del Inventari de Jaciments Paleontològics de la Comunitat Valenciana, base de datos que, por ahora, únicamente incluye una fracción mínima de los yacimientos existentes en el territorio valenciano.

Lo anteriormente expuesto demuestra que no puede obviarse la legislación en materia cultural en lo referente a este tipo de bienes. Tras la derogación de las figuras de protección de espacios naturales sitio de interés y paraje natural (LEY 5/2013), la legislación valenciana establece a través de la Ley 11/1994 cinco figuras distintas para la protección de los espacios naturales: parque natural, paraje natural municipal, reserva natural, monumento natural y paisaje protegido. De entre todas las figuras de protección establecidas por dicha ley, el patrimonio paleontológico puede integrarse en las figuras de paraje natural municipal (Art. 9) o monumento natural (Art. 11). Si bien en el artículo 11 se cita explícitamente que los yacimientos paleontológicos podrán ser incluidos como monumento natural, la diferencia entre esta figura y la de paraje natural municipales es de carácter cualitativo. La ley establece que en el monumento natural se incluirían aquellos "espacios o elementos de la naturaleza,..., de notoria singularidad, rareza o belleza, que merecen ser objeto de una protección especial por sus valores científicos, culturales o paisajísticos". La última parte de la definición pone de manifiesto esa diferencia cualitativa entre ambas figuras de protección, ya que como paraje natural municipal se entiende que son zonas “...que presenten especiales valores naturales de interés local que requieran su protección, conservación y mejora y sean declaradas como tales a instancias de las entidades locales". El hecho de que la declaración de estos espacios sea iniciativa de la administración local es un interesante punto de partida para fomentar el conocimiento de este patrimonio y la inclusión de estos como elementos decisivos en la definición de los PGOU locales. Es necesario un nuevo paradigma en lo que se refiere al papel de los espacios protegidos, en donde su gestión busque el interés público, y por tanto sea uno de los elementos nucleares del proceso. No se puede pretender proteger la naturaleza sin incorporar a las comunidades locales que habitan a su alrededor. En nuestra opinión, la figura de paraje natural municipal, tal y como contempla la legislación valenciana de protección de espacios naturales, podría ser un buen punto de partida para incorporar el patrimonio paleontológico en el acervo natural de un municipio, región, etc.

\section{BIBLIOGRAFÍA}

- CASTILlO, C.; CASTILLO, J.; COELLO, J. J.; MARTÍN, E.; MARTíN, M.; MÉNDEZ, A. (1999) La tutela del Patrimonio Paleontológico en Canarias. Valoración general. Coloquios de Paleontología, n. ${ }^{\circ}$ 50, 1999, pp. 9-21

- LEY 11/1994, de 27 de diciembre, de la Generalitat Valenciana, de Espacios Naturales Protegidos de la Comunidad Valenciana. Diari Oficial de la Comunitat Valenciana, n. ${ }^{\circ} 2423$, de 09 de enero de 1995

- LEY 4/1998, de 11 de junio, del Patrimonio Cultural Valenciano. Diari Oficial de la Comunitat Valenciana, n. ${ }^{\circ} 3267$, de 18 de junio de 1998

- LEY 5/2013, de 23 de diciembre, de Medidas Fiscales, de Gestión Administrativa y Financiera, y de Organización de la Generalitat. Diari Oficial de la Comunitat Valenciana, n. ${ }^{\circ} 7181$, de 27 de diciembre de 2013

- MORALES, J.; AZANZA, B. (1997) Los parques paleontológicos, una alternativa de gestión para recursos paleontológicos de alto potencial didáctico, cultural y artístico. En PALLI, L.; CARRERAS, J. (dir.) Comunicaciones de la II Reunión Nacional de la Comisión Patrimonio Geológico. Girona: Sociedad Geológica de España, Universidad de Girona, 1997, pp. 51-54

- RUIZ SÁNCHEZ, F. J. (2005) La legislación de medio ambiente y la protección del patrimonio paleontológico en la Comunidad Valenciana (España). Revista Española de Paleontología, n. ${ }^{\circ}$ extraordinario X. XIX Jornadas de Paleontología, 2005, pp. 119-124 